\title{
OCORRÊNCIA DE CLOSTRIDIUM DIFFICILE EM LEITÕES SUBMETIDOS À ANTIBIOTICOTERAPIA NAS REGIÕES DE SANTA CATARINA
}

\author{
Carolina Grasel Barbosa, ${ }^{1}$ Beatriz Dugaich, ${ }^{2}$ Thomas Bierhals, ${ }^{2}$ Paulo Zuffo, ${ }^{3}$ \\ Priscilla Karina Vítor Koerich Henn ${ }^{3}$ e Eliana Knackfuss Vaz ${ }^{4}$ \\ 1. Departamento de Microbiologia/Sanidade Suína, Universidade do Estado de Santa Catarina \\ 2. Aluna-bolsista de Iniciação Cientifica, CAV/UDESC \\ 3. Médico veterinário, Perdigão Agroindustrial S.A. \\ 4. Professora orientadora, Centro de Ciências Agroveterinária (CAV/UDESC).
}

RESUMO

O Clostridium difficile é um bastonete oportunista Grampositivo, anaeróbio obrigatório, formador de esporos, encontrado no solo, água e microbiota entérica de várias espécies animais. Tem sido descrito como causa de enterite em seres humanos e animais. Em suínos tem adquirido grande importância, devido ao grande número de casos de enterites neonatais que afeta o cólon de leitões entre um a sete dias de idade. Essa bactéria produz dois tipos de toxinas, A (enterotóxica) e B (citotóxica), que possuem papel importante na patogênese da doença. Com o objetivo de pesquisar a presença da bactéria em leitões com até sete dias de idade submetidos à antibioticoterapia bem como a produção das toxinas A e B nas amostras isoladas, realizaram-se oito coletas em diferentes regiões do Estado de Santa Catarina, totalizando 490 amostras de fezes e suabes retais de leitões, coletados no período de janeiro a março de 2008. Os suabes retais foram processados no mesmo dia da coleta no Laboratório de Microbiologia (CAV/ UDESC) e as fezes foram congeladas a $-4{ }^{\circ} \mathrm{C}$ em ependorf estéril para posterior realização do teste de ELISA. Foram isoladas 23 amostras do $C$. difficile, sendo que nenhuma delas produziu as toxinas A e B, pela análise do teste do ELISA. Já das 69 amostras de fezes analisadas, $32(46,37 \%)$ foram positivas para a presença das toxinas, $3(4,34 \%)$ intermediárias e 34 (49,27\%) negativas, conforme demonstrou o teste de ELISA.

PALAVRAS-CHAVES: Antibiótico, Clostridium difficile, diarreia, suínos.

\section{ABSTRACT}

\section{OCURRENCE OF CLOSTRIDIUM DIFFICILE IN PIGS SUBMITTED TO ANTIBIOTIC THERAPY IN SANTA CATARINA STATE}

The Clostridium difficile is a Gram-positive opportunist, anaerobic, spore-forming rod found in the soil, water and enteric microbiota of many animal species. It has been described as the cause for enteritis in human beings and animals. In swine it has grown in importance due to the large number of cases of neonatal enteritis that affects the colon of one to seven-day-old piglets. This bacterium produces two kinds of toxins: A (enterotoxin) and B (cytotoxin). They have an important role in the disease's pathogenesis. Aiming at researching the presence of the bacterium in up to seven days piglets submitted to antibiotic therapy as well as the production of the toxins $\mathrm{A}$ and $\mathrm{B}$ in isolated samples, 8 collections were made in different regions of the state of Santa Catarina, totalizing 490 samples of stool and retal swabs of piglets, gathered in the period of January to March 2008. The retal swabs were processed in the same day they were collected in the Microbiology Lab of CAV/UDESC and the stools were frozen at $-4^{\circ} \mathrm{C}$ in steril Ependorf so that they could be submitted to the ELISA test later. Twenty-tree colonies of $C$. difficile were isolated, but no one produced the $\mathrm{A}$ and $\mathrm{B}$ toxins according to the ELISA test. Of the 69 stools analyzed, $32(46.37 \%)$ were positive samples, 3 (4.34\%) were intermediate samples, and 34 (49.27\%) were negative samples, according to the ELISA test.

KEYWORDS: Antibiotic, Clostridium difficile, diarrhea, swine. 


\section{INTRODUÇÃO}

Clostridium difficile é uma bactéria Grampositiva, anaeróbia, formadora de esporos, encontrada no meio ambiente e no trato intestinal de vários mamíferos, pássaros e répteis (NAGY \& BILKEI, 2003). Este agente é responsável por causar uma colite pseudomembranosa e diarreia associada ao uso de antibióticos em humanos, cavalos e em animais de laboratório (POST et al., 2004). Recentemente foi reconhecido como agente etiológico responsável por causar enterites em leitões (WATERS et al., 1998; SONGER et al., 2000).

Nos últimos anos a infecção causada pelo $C$. $d i$ fficile tem adquirido significativa importância, podendo ser a causa de mais de $50 \%$ das diarreias neonatais em leitões na primeira semana de vida e pela morte de até $10 \%$ dos leitões nas maternidades (SONGER et al., 2004). Nos EUA, as cepas toxigênicas do $C$. difficile são consideradas o principal agente etiológico e o único responsável por $35 \%$ das diarreias neonatais, além de ser encontrado em associação com outros enteropatógenos em $25 \%$ de outros casos de enterite (SONGER et al., 2007; MASARIKOVÁ et al., 2008).

A doença causada pelo $C$. difficile tem sido frequentemente associada ao uso de antibióticos, que levam a uma alteração na microbiota entérica e oportunizam a colonização pelo agente. Quando ocorrem alterações nessa microbiota, bactérias resistentes a antimicrobianos podem se multiplicar, inibindo o crescimento das bactérias benéficas ao trato intestinal e favorecendo, assim, o crescimento de bactérias patogênicas, como o C. difficile (FURTADO et al., 2005).

Os leitões apresentam dispneia moderada, distensão abdominal e edema escrotal. Ocasionalmente têm diarreia, ascite, hidrotórax, dificuldade respiratória, e alta morbidade e mortalidade podem ocorrer. As lesões macroscópicas são enterite inflamatória, edema de mesocólon e na microscopia encontra-se acúmulo de neutrófilos e fibrina na lâmina própria (SONGER et al., 2000). O C. difficile produz as toxinas $\mathrm{A}$ e $\mathrm{B}$, que são as principais responsáveis pelo desencadeamento da doença.

O diagnóstico da infecção pelo $C$. difficile é realizado pela detecção das toxinas e pelo isolamento da bactéria em meio de cultura específico. O simples isolamento da bactéria tem valor limitado, pois o agente pode ser encontrado em leitões saudáveis. Para o diag- nóstico definitivo, faz-se necessária a identificação das toxinas A e B nas fezes, utilizando-se o teste de ELISA (SOBESTIANSKY \& BARCELLOS, 2007).

A proposta deste estudo foi determinar a ocorrência do Clostridium difficile no Estado de Santa Catarina em leitões submetidos à antibioticoterapia e, por meio das amostras isoladas, verificar quais produziram as toxinas A e B pelo teste de ELISA.

\section{MATERIAL E MÉTODOS}

Para realização do presente estudo as amostras do material foram obtidas de maternidades de suínos localizadas nas seguintes regiões de Santa Catarina: Vale do Itajaí (Rio do Sul e Ituporanga), Meio-Oeste Catarinense (Concórdia, Jaborá, Luzerna e Erval Velho) e região Sul (Braço do Norte e São Ludgero), no período de janeiro a março de 2008. Foram coletados aleatoriamente amostras de fezes e suabes retais de 490 leitões com um a sete dias de idade, tratados com antibióticos de amplo espectro no primeiro dia de vida. Colocaram-se os suabes retais no meio de transporte Amies com carvão, específico para bactérias anaeróbicas, e as fezes em ependorf estéreis, todos acondicionados em caixas de isopor com gelo reciclável e transportados até o Laboratório de Microbiologia do CAV - UDESC. Os suabes retais foram processados no mesmo dia das coletas, e as fezes foram congeladas a $-20{ }^{\circ} \mathrm{C}$ para posterior realização do teste de ELISA para identificação das toxinas A e B.

No Laboratório, o meio de cultura seletivo ágar cicloserina-cefoxitina frutose (CCFA), específico para o isolamento do Clostridium difficile, foi preparado de acordo com GEORGE (1979). Suplementou-se o CCFA com $0,5 \mathrm{~mL}$ de taurochocolate de sódio adicionado após a esterilização deste. Os suabes retais foram semeados pela técnica de esgotamento neste meio e incubados anaerobicamente por 48 horas a $37^{\circ} \mathrm{C}$ em jarras com Gapak, que proporcionou uma atmosfera com os seguintes gases: N2 (80\%), CO2 (10\%) e H2 (10\%). Após esse período, primeiramente, analisou-se a morfologia das colônias suspeitas e logo em seguida fez-se a coloração de Gram dessas colônias, para a identificação dos bacilos Gram-positivos.

Os isolados foram confirmados bioquimicamente pelo teste da motilidade, produção de indol 
e hidrólise de gelatina. Incubaram-se as colônias isoladas no meio de enriquecimento $\mathrm{BHI}$, por 48 horas nas mesmas condições anteriores, sendo após congeladas.

O teste de ELISA foi utilizado para determinar qualitativamente a produção das toxinas A e B pelo Clostridium difficile nas amostras de fezes e nas colônias isoladas. Empregaram-se as primeiras 46 unidades do kit ELISA para correlacionar a produção das toxinas pelas colônias isoladas com a produção das toxinas das suas respectivas fezes. Utilizou-se o restante do teste somente na análise das fezes. O teste foi executado cinco meses após a realização da última coleta, no laboratório de sorologia da Perdigão. O kit RIDASCREEN ${ }^{\circledR}$ Clostridium difficile Toxina A/B da empresa R-BIOPHARM utiliza anticorpos monoclonais contra as toxinas A e B do Clostridium difficile. Para a avaliação e interpretação dos resultados, procedeu-se ao cálculo do CUT - Off (ponto de corte). As amostras cujo valor de absorbância fica mais de $10 \%$ acima do CUT-OFF calculado foram consideradas positivas e as amostras que ficam mais de $10 \%$ abaixo do CUTOFF calculado foram consideradas negativas, sempre seguindo as instruções do fabricante.

\section{RESULTADOS E DISCUSSÃO}

O Clostridium difficile é o principal agente etiológico das diarreias associadas ao uso de antibiótico e da colite pseudomembranosa em humanos. Em suínos, ele é o agente responsável por causar diarreia e morte em leitões de 1 a 7 dias de idade. Entretanto, ainda há poucos dados publicados sobre a sua importância na suinocultura brasileira.

No presente trabalho, foi possível isolar 23 (4,7\%) amostras do Clostridium difficile, de um total de 490 coletadas de suabes retais. No meio CCFA, as colônias se apresentaram acinzentadas, não hemolíticas, circulares, rugosas, salientes e modificavam a cor do meio, do mesmo modo como descrito por GEORGE (1979). Por meio da coloração de Gram, verificou-se a presença de bacilos Gram-positivos. Nos testes bioquímicos, o indol foi negativo, as bactérias se mostraram imóveis e hidrolisaram a gelatina, caracterizando, assim, o Clostridium difficile (MERZ et al., 1994).

Os resultados do teste do ELISA para avaliar a produção das toxinas pelas fezes e pelas colônias constam na Tabela 1. O kit de ELISA foi dividido em três grupos. No primeiro, verificou-se a produção das toxinas A e B pelas colônias isoladas. No segundo, correlacionou-se a produção das toxinas pelas colônias com as suas respectivas fezes. No terceiro, utilizaram-se somente as fezes. Das 23 amostras isoladas, nenhuma produziu as toxinas, pela análise do teste de ELISA. Já das 22 amostras de fezes correlacionadas com as colônias, 11 (50\%) foram positivas. Por conseguinte, analisaram-se 47 amostras de fezes, sendo que $20(42,55 \%)$ amostras foram positivas, $3(6,38 \%)$ amostras foram intermediárias e $24(51,06 \%)$ amostras foram negativas, totalizando 69 amostras de fezes analisadas, 31 $(44,95 \%)$ amostras positivas. Analisaram-se somente 69 amostras de fezes das 490 coletadas, pelo fato de o kit de ELISA utilizado ter capacidade para 92 amostras. As amostras de fezes foram selecionadas aleatoriamente.

No meio de cultura CCFA, observou-se o crescimento de outras bactérias, que não foram características na coloração de Gram e nem nos testes bioquímicos. As colônias dessas bactérias eram menores e não possuíam as características morfológicas do C. difficile.

TABELA 1. Resultados da produção das toxinas A e B no teste de ELISA coletados de leitões em Santa Catarina no período de janeiro a março de 2008

\begin{tabular}{lcccc}
\hline & Positivo & Intermediário & Negativo & Total \\
\hline Colônias & 0 & 0 & 23 & 23 \\
Colônias x fezes & 11 & 0 & 11 & 22 \\
Fezes & 20 & 3 & 24 & 47 \\
Total & 31 & 3 & 58 & 92 \\
\hline
\end{tabular}


O CCFA é um meio de cultura seletivo e diferencial, considerado o melhor meio para o isolamento do $C$. difficile. As colônias do $C$. difficile que crescem neste meio são morfologicamente diferentes e trazem propriedades fluorescentes suficientes para uma identificação presuntiva. Apresentam em sua formulação os antibióticos cicloserina e cefoxitina, que inibem parcialmente o crescimento de outras bactérias. A escolha desses antibióticos como componentes do meio foi baseado no nível de resistência das 16 cepas do $C$. difficile à cefoxitina (concentração inibitória mínima $\geq 32 \mu \mathrm{g} / \mathrm{mL}$ ) e à cicloserina (concentração inibitória mínima $\geq 1,024 \mu \mathrm{g} / \mathrm{mL}$ ) (GEORGE et al., 1979).

O isolamento das colônias do $C$. difficile é considerado por muitos autores o melhor método de diagnóstico, embora a pesquisa das toxinas precise ser executada para diferenciar as cepas toxigênicas das não toxigênicas (MERZ et al., 1994). RELLER et al. (2007) sugeriram que a colônia é mais sensível que as fezes para detecção das cepas toxigênicas do $C$. difficile, porém o isolamento da colônia é demorado, trabalhoso e difícil de ser realizado.

Neste estudo, o $C$. difficile foi isolado de amostras fecais de 4,7\% (23/490) leitões, diferentemente do encontrado por YAEGER et al. (2007), em que se isolou o $C$. difficile do intestino grosso de 47\% (61/129). Essa diferença pode ser explicada por vários fatores, incluindo os efeitos dilucionais da diarreia, dificuldade de isolamento e o congelamento prolongado (GEORGE et al., 1979). No Brasil não existem trabalhos publicados sobre o isolamento do $C$. difficile em leitões.

Em $50 \%(11 / 22)$ dos leitões o isolamento do C. difficile e a produção da toxina foram negativos, e em nenhum dos leitões a cultura e a produção das toxinas foram positivas. Isso se deve ao fato de nenhuma colônia ter produzido as toxinas. Resultados diferentes foram encontrados por YAEGER et al. (2007) nos Estados Unidos, em que 31\% (40/129) dos leitões mostraram-se negativos para ambas - cultura e produção da toxina - e, em 35\% (45/129) dos leitões, cultura e produção das toxinas mostraram-se positivas. As hipóteses mais prováveis para explicar esses resultados referem-se ao fato de as amostras poderem indicar a presença de cepas não toxigênicas ou porque foram congeladas a $-20{ }^{\circ} \mathrm{C}$ ou pelo descongelamento delas, mais de uma vez, pois assim pode ocorrer uma rápida perda da atividade citotóxica (WALTERS et al., 1998; DELMÉE et al., 2001).

Já as toxinas das amostras de fezes foram detectadas em 44,95\% (31/69) leitões em que o isolamento foi negativo. Esses resultados são semelhantes aos reportados no trabalho realizado por YAEGER et al. (2007), em que se detectaram as toxinas no conteúdo do colón de 50\% (65/129) dos leitões.

A detecção das toxinas nas fezes e não nas colônias isoladas pode estar relacionada ao fato de as fezes serem mais resistentes ao congelamento que as colônias, pois, aparentemente, neste estudo a interferência do congelamento parece ter sido menor, visto que, em 44, $92 \%$ das amostras, detectou-se toxina nas fezes e não nas colônias. No total de 69 amostras de fezes analisadas, 32 $(46,37 \%)$ apresentaram as toxinas, demonstrando que as fezes são o melhor material para a detecção delas.

Para a detecção das toxinas A e B do C. difficile nas fezes ou no conteúdo intestinal de leitões, POST et al. (2002) compararam o teste de efeito citotóxico em cultivo celular com o teste de ELISA. Das 50 amostras analisadas, 20 foram positivas e 24 foram negativas para ambos os testes, gerando uma correlação de $88 \%$. A sensibilidade e a especificidade foram de $91 \%$ e $86 \%$, respectivamente. Desse modo, o teste de ELISA foi considerado um adequado método para o diagnóstico da CDAD.

Resultados semelhantes ao deste trabalho foram encontrados por ANDERSON (2008), que verificou que a detecção da toxina do Clostridium difficile nas fezes é o elemento-chave para o diagnóstico da CDAD (doença associada ao Clostridium difficile) em humanos e animais, e o teste de ELISA é desejável, dada a sua economia e o tempo de trabalho.

Em trabalho recentemente publicado por LIPPKE (2008), observou-se que em leitegadas sem diarreia os coccídeos $(8,5 \%)$ e o $C$. difficile $(16,6 \%)$ foram os agentes mais frequentemente encontrados, $\mathrm{e}$ em leitegadas com diarreia o $C$. difficile foi observado em $10,6 \%$, não ocorrendo diferença significativa na presença entre as leitegadas caso e controle. A explicação para esses resultados, de acordo com YAEGER et al. (2007), se deve ao fato de a detecção das toxinas A e B não representar um bom indicador para a presença ou ausência de diarreia. Já foi observado, em um estudo caso-controle, que a maioria (59\%) dos leitões positivos para as toxinas A e B não apresentou 
diarreia em comparação com os leitões negativos para as duas toxinas. Especula-se que possa haver algum outro fator, além das toxinas A e B, que seja essencial para o desencadeamento da diarreia.

Não se observou associação entre a maior quantidade de toxinas detectadas nas fezes e diarreia e também não foram correlacionados os tipos de fezes com a produção de toxinas (LIPPKE, 2008).

Todas as amostras coletadas referem-se a leitões com um a sete dias de idade. Entretanto, as amostras de fezes positivas para a produção da toxina concernem leitões com até quatro dias. Dados semelhantes foram encontrados por LIPPKE (2008), em que, assim, como a toxina beta do Clostridium perfringens, as toxinas A e B do $C$. difficile são destruídas pela ação da tripsina, fazendo com que a ocorrência de casos de infecção por esse agente concentre-se no início do período neonatal.

\section{CONCLUSÃO}

Foi possível verificar a ocorrência do C. difficile no Estado de Santa Catarina, isolando o agente de leitões de 1 a 7 dias de idade submetidos à antibioticoterapia. O meio seletivo ágar cicloserina-cefoxitina frutose foi eficiente para o isolamento do $C$. difficile. Nenhuma amostra isolada do $C$. difficile produziu as toxinas A e B, quando submetidas ao teste de ELISA. Foi possível detectar a presença das toxinas A e B do C. difficile das fezes e suabes retais de leitões com até quatro dias de idade.

\section{AGRADECIMENTOS}

Aos médicos veterinários Priscila Koerich e João Zuffo, da PERDIGÃO S. A., Videira, SC.

\section{REFERÊNCIAS}

ANDERSON, M. A.; SONGER, J. G. Evaluation of two enzyme immunoassays for detection of Clostridium difficile toxins A and B in Swine. Veterinary Microbiology, v. 128, p. 204-206, 2008.

DELMEÉ, M. Laboratory diagnosis of Clostridium difficile disease. Clinical Microbiology and Infection, v. 7, p. 411-416, 2001.

FURTADO, C. S. D.; KOLLER, F. L.; ASANOME; BARCELLOS, D. E. Clostridium difficile: um grande problema ainda pouco conhecido. Suinocultura em Foco, v. 5, n. 14, p. 4, 2005.
GEORGE, W. L.; SUTTER, V. L.; CITRON, D; FINEGOLD, S. F. Selective and differencial medium for isolation of Clostridium difficile. Journal of Clinical Microbiology, v. 9, n. 2, p. 214-219, 1979.

LIPPKE, R. T. Estudo caso-controle avaliando a freqüência dos principais agentes causadores de diarreia neonatal em suínos. 2008. 70 f. Dissertação (Mestrado de Ciências Veterinárias) - Curso de Pós-Graduação em Ciências Veterinárias na área de Medicina Veterinária Preventiva, Universidade Federal do Rio Grande do Sul, Porto Alegre, 2008. Disponível em: <http://www.lume.ufrgs.br/>.

MASARIKOVÁ, M. Clostridium difficile-associated disease (CDAD) in czech piglet production. In: IPVS CONGRESS, 20., 2008, Durban. Proceedings... Durban, 2008, v. 3, p. 251.

MERZ, C. S.; KRAMER, C.; FORMAN, M.; GLUCK, L.; MILLS, K.; SENFT, K.; STEIMAN, I.; WALLACE, N.; CHARACHE, P. Comparison of four commercially available rapid enzyme immunoassays with cytotoxin assay for detection of Clostridium difficile toxin from stool specimens. Journal of Clinical Microbiology, v. 32, n. 5, p. 1142-1147, 1994.

NAGY, J.; BILKEI, G. Neonatal piglet losses associated with Escherichia coli and Clostridium difficile infection in a Slovakian outdoor production unit. The Veterinary Journal, v. 166, p. 98$100,2003$.

POST, K. W.; JOST, B. H.; SONGER, J. G. Evaluation of a test for Clostridium difficile toxins A and B for the diagnosis of neonatal swine enteritis. Journal of Veterinary Diagnostic Investigation, v. 14 , p. $258-259,2002$.

RELLER, M. E.; LEMA, C. A.; PERL, T. M.; CAI, M.; ROSS, T. L.; SPECK, K. A.; CARROLL, K. C. Yield of stool culture with isolate toxin testing versus a two-step algorithm including stool toxin testing for detection of toxigenic Clostridium difficile. Journal of Clinical Microbiology, v. 45, n. 11, p. 3601-3605, 2007.

SOBESTIANSKY, J.; BARCELLOS, D. Bacterioses. In: BARCELLOS, D.; OLIVEIRA, S. J. Doenças dos suínos. 2. ed. Brasil: Cânone, 2007. p. 103-104.

SONGER, J. G.; JONES, R.; ANDERSON, M. A; BARBARA, A. J.; POST, K. W.; TRINH, H. T. Prevention of porcine Clostridium diffcile: associated disease by competitive exclusion with nontoxigenic organisms. Veterinary Microbiology, v. 124, p. 358-361, 2007.

SONGER, J. G.; POST, W. P.; LARSON, D. J.; JOST, H.; GLOCK, R. D. Infection of neonatal swine with Clostridium difficile. Swine Health and Production, v. 8, n. 4, p. 185-189, 2000.

SONGER, J. G. The emergence of Clostridium difficile as a pathogen of food animals. Animal Health Research Reviews, v. 5, n. 2, p. 321-326, 2004. 
WATERS, E. H.; ORR, J. P.; CLARK, E. G.; SCHAUFELE, C. M. Typhlocolitis caused by Clostridium difficile in suckling piglets. Journal of Veterinary Diagnostic Investigation, v. 10, p. 104-108, 1998. difficile toxins in the colon of neonatal swine and gross and microscopic lesions. Journal of Veterinary Diagnostic Investigation, v. 19, p. 52-59, 2007.

YAEGER, M. J.; KINYON, J. M.; SONGER, J. G. A prospective, case control study evaluating the association between Clostridium

Protocolado em: 10 dez. 2008. Aceito em: 24 ago. 2010. 